\title{
Automatic Velocity Control in Cutting-off Machines
}

\author{
Carlos Machado ${ }^{1}$, Jaime Fonseca ${ }^{2}$ and José Mendes ${ }^{3}$ \\ University of Minho \\ 1,2,3 Dept. of Industrial Electronics \\ Campus de Azurem, Portugal \\ Phone: +351253510190 , Fax:+351253510189 \\ e-mail: \{carlos.machado | jaime.fonseca | jose.mendes \}@dei.uminho.pt \\ ${ }^{3}$ Addressee for correspondence
}

\begin{abstract}
Usually, automatic cutting-off machines, of metallic pipes or bars, use constant cutting velocity. This mode of operation, constant cutting velocity combined with different profiles of materials to be cut, causes variable cutting forces to be applied to the saw. As a result, the cutting off machine is generally set for the worst expected conditions, otherwise excessive wear of the saw and machine will occur. Further, traditional cutting-off machines require adjustments to be made in order to automatically detect the completion of a cut. The objective of this project is the study of the application of control algorithms to the process of cutting-off metallic pipes or bars, with variable profiles, implemented in an industrial cutting-off machine, commercially available. The testes algorithms concern real-time cutting control and automatic detection of cut completion. The algorithms are implemented in a low cost Programmable Logic Controller (PLC), allowing its adoption in industrial applications without significant increase on machine cost. All algorithms were developed having in mind safety issues relative to the operation of the cutting machine in order to prevent damage to the machine itself.. Also, all process related relevant parameters are monitored on a Personal Computer using OPC (Object Linking and Embedding - for Process Control).
\end{abstract}

Index Terms - Automatic velocity control cutting-off

\section{Introduction}

Usually, automatic cutting-off machines, adopt a constant cutting velocity mode. This mode of operation, constant cutting velocity combined with different profiles of materials to be cut, causes variable cutting forces to be applied to the saw. As a result, the cutting off machine is normally set for the worst expected conditions, otherwise excessive wear of the saw and machine will occur.

On one hand, if the cutting velocity is too high the worn of the saw as well as the components of the machine are too high. On the other hand, if the cutting velocity is too slow the cutting time significantly increases, reducing productivity of the automatic cutting machine. Further, traditional cutting-off machines require the adjustment of the position of a limit switch in order to automatically detect when the cut of a piece has been completed.

In this project, different control algorithms were developed and applied in order to optimize the cutting process by diminishing cutting times and maximizing life time of the saw and machine components. Also, a new method for automatic detection of the completion of the cutting of a piece was developed, therefore neither a limit switch nor its adjustment is any longer necessary [1].

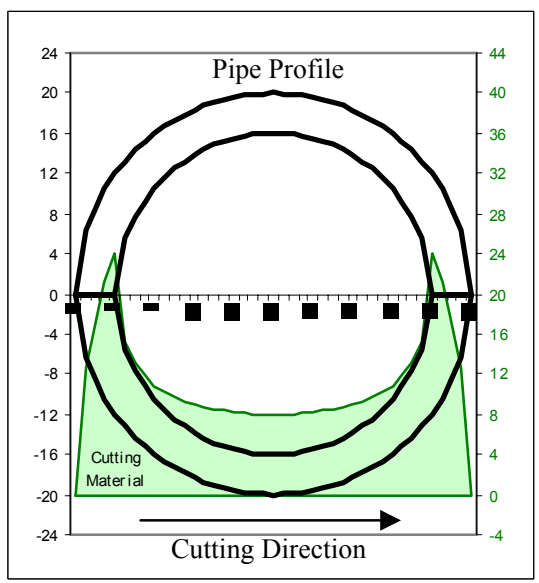

Fig. 1: Pipe Cutting.

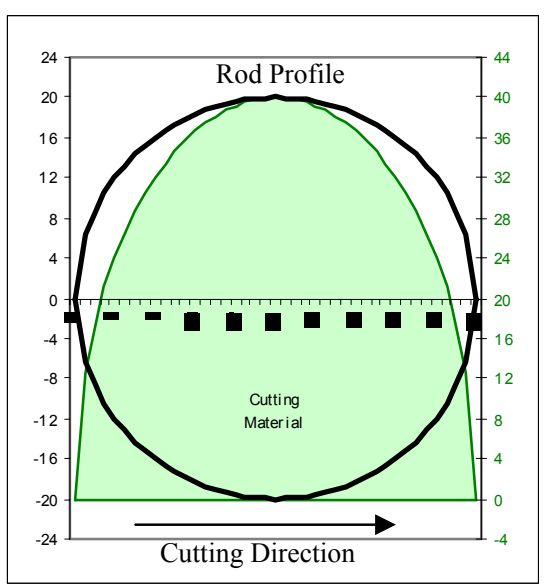

Fig. 2: Rod Cutting.

\section{Description}

In Figure 1 and Figure 2, respectively, the profile of a tube and a rod are shown. If materials with such profiles are to be cut, the exact amount of material that has to be removed at a specific point is also shown, assuming that cutting is performed by a linear saw.

The amount of material to be removed is closely linked to the required torque to be applied on the saw. The cutting torque requirements depend on the profile of the pipe, rod or bar, as shown in Figures 1 and 2. 
In Figure 1, the required cutting torque is higher at the beginning and at the end of the profile rather than in the middle of the pipe. In the middle region of the pipe, the required torque has its lowest value, because in this region the amount of material to be removed is minimum. On the opposite, when a rod is cut, the required cutting torque in its middle region is maximum, because more material has to be removed.

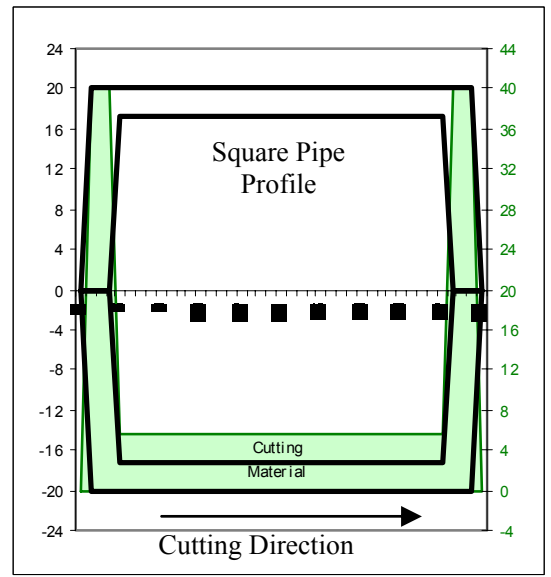

Fig. 3: Square Pipe Cutting.

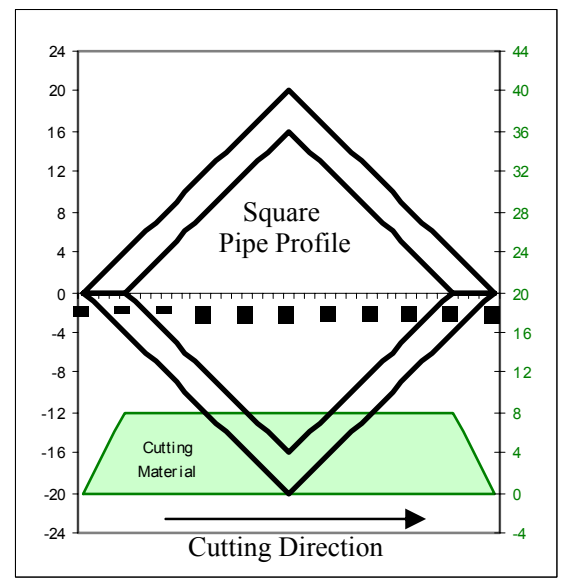

Fig. 4: Square Pipe Cutting at $45^{\circ}$.

The cutting of rectangular or square profiles, either hollow or not, have considerably different cutting torque requirements.

In Figure 3 and Figure 4, the same square profile is shown in two different cutting positions. The cutting torque requirements for each position are also presented. In Figure 3, the required cutting torque has two peaks, one at the beginning and another one at the end of the cut, with a middle region characterised by low torque requirements. In Figure 4, the required cutting torque is constant. Therefore, the position of cutting of a profile is not indifferent. Actually, the position shown in Figure 4 is the most appropriate for constant velocity cutting-off. However, it is not always possible to get the optimal cutting position due to mechanical limitations of the cutting off machine, as well as shapes to be obtained from cutting.

\subsection{Cutting-off using a circular saw}

The cutting-off process, using a circular saw (see Figure 5), depends on two factors, namely, the angular saw disc velocity (tangential velocity) and forward saw disc velocity (perpendicular velocity). These two parameters are closely related and need to be properly set-up in order to assure a good quality cutting-off. If the forward velocity is to fast relatively to the angular velocity, it will cause a too high pull-off of material by each saw tooth, which in turn causes damage to the teeth and a low quality cuttingoff. On the opposite, if the forward velocity is too slow, a polishing effect is obtained. Consequently, greater heating of the pipe and saw occur, originating changes on the characteristics of the material to be cut as well as the characteristics of the circular saw.

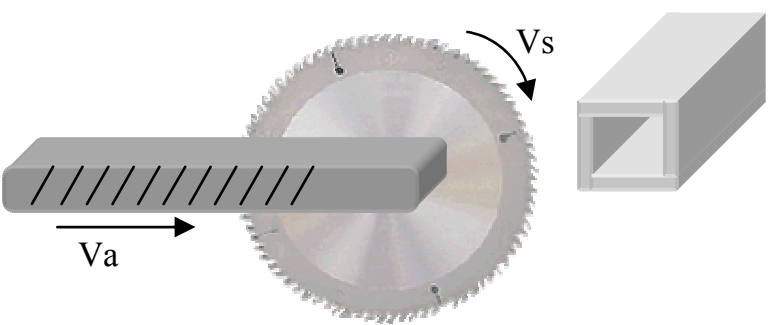

Fig. 5: Cutting-off with a circular saw.

The set-up of these velocities depends on several factors, namely, the type of material to be cut, diameter of the circular saw, number of teeth of the circular saw and shape of the teeth of the circular saw. Saw manufacturers provide the adequate range of velocity for the saw as well as the forward velocity according to the material to be cut.

\begin{tabular}{|c|c|c|}
\hline \multicolumn{3}{|c|}{ Saw Disc - STARK } \\
\hline $\begin{array}{c}\text { Material } \\
\text { to cut }\end{array}$ & $\begin{array}{l}\text { Saw cut velocities } \\
(V)[\mathrm{m} / \mathrm{min}]\end{array}$ & $\begin{array}{l}\text { Forward / Teeth } \\
(\mathrm{Az})[\mathrm{mm}]\end{array}$ \\
\hline Steel, $500 \mathrm{~N} / \mathrm{mm}^{2}$ & {$[30 \ldots 50]$} & {$[0,03 . .0,06]$} \\
\hline Steel, $800 \mathrm{~N} / \mathrm{mm}^{2}$ & {$[20 \ldots 40]$} & {$[0,03 . .0,04]$} \\
\hline Steel, $1200 \mathrm{~N} / \mathrm{mm}^{2}$ & {$[15 \ldots 25]$} & {$[0,02 \ldots 0,03]$} \\
\hline Inox Steel & {$[10 \ldots 50]$} & {$[0,01 \ldots 0,03]$} \\
\hline
\end{tabular}

Table 1- Stark Saw Disc range of cutting velocities

The circular saw angular velocity $(V S)$ is determined from the linear cutting velocity (V) and the saw diameter (D):

$$
V s=\frac{V \times 1000}{D \times \pi}(\mathrm{rpm})
$$

The forward velocity ( $\mathrm{Va}$ ) is the product of the saw angular velocity $(V S)$, the number of saw teeth $(\mathrm{Z})$ and the forward displacement per teeth $(\mathrm{Az})$ :

$$
V a=V s \quad x \quad Z x A z
$$

The parameterization of the cutting process on the cuttingoff machine demands from the user the knowledge of the saw disc trademark, diameter of the saw, number of teeth of the saw as well as the material type. The allowed 
velocity ranges are previously stored in a table organized by trademark and cutting material. From the combination of trademark of saw disc and material to be cut, ranges for the saw angular velocity and forward velocity are established, thus assuring that cutting-off process runs in optimal conditions.

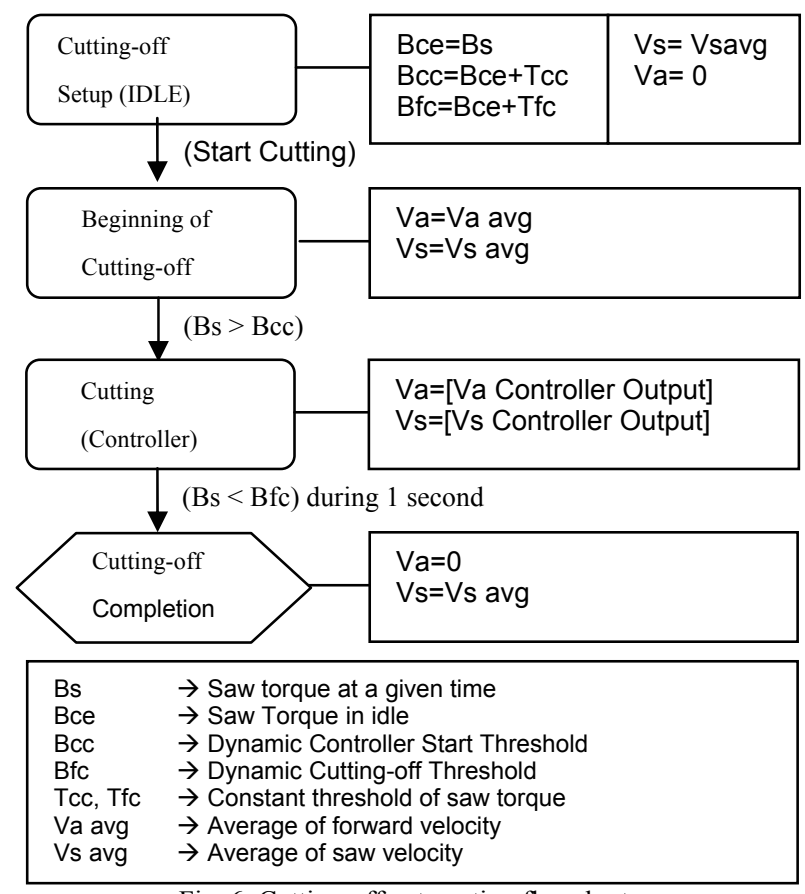

Fig. 6: Cutting-off automation flowchart.

\subsection{Cutting-off Automation}

The automation cutting-off process can be divided in four main stages: 1) cutting off set up, 2) beginning of cutting-off, 3) cutting off and 4) cutting-off completion. In the first stage (cutting off set up), the cutting off torque of the motor that drives the saw disc (Bce) is read in idle. This value is used in dynamic threshold calculations necessary for subsequent stages. This stage is very important as cutting conditions, like temperature of machine, vary throughout the day. The second stage (beginning of cutting off) objective is a smooth beginning of the cutting off process, i.e., the initial contact between saw and material velocity needs to be per-formed at low speed. The third stage comprises the automatic velocity control in cutting of the material according to the implemented controller (see Figure 7), which is responsible for the continuous adjustment of angular and forward velocities of the saw. Finally, the cutting off completion stage objective is the automatic detection of when the material has been completely cut, independently of its profile.

Stage switching is achieved using two dynamic thresholds calculated from the applied torque by the motor which drives the saw disc: - Cutting off Control Threshold (Bcc) and Cutting off Completion Threshold (Bfc).

The torque applied by the saw disc (Bs) is filtered using a low pass filter, thus eliminating the over imposed noise generated by the contact between the saw disc teeth and the material to be cut.
Switching from the second stage to the cutting off stage occurs as soon as the saw disc filtered torque is greater that the Cutting Control Threshold (Bcc). Switching from the cutting off stage to the last stage happens when the saw disc filtered torque is lower than the Cutting off Completion Threshold (Bfc) for a period of at least one second.

On the second stage, beginning of cutting off, the initial angular velocity of the saw disc and initial forward velocity are set as the average value of the range of allowed values supplied by the saw disc manufacturer according to the type of material being cut.

In Figure 7, it is shown cutting-off machine diagram. In this system, there are two feedback loops in order to control the motor velocities. The cutting-off controller is implemented in a PLC, using the saw torque read from the saw velocity driver analogue output. The PC gets the process main variables from the PLC, using OPC.

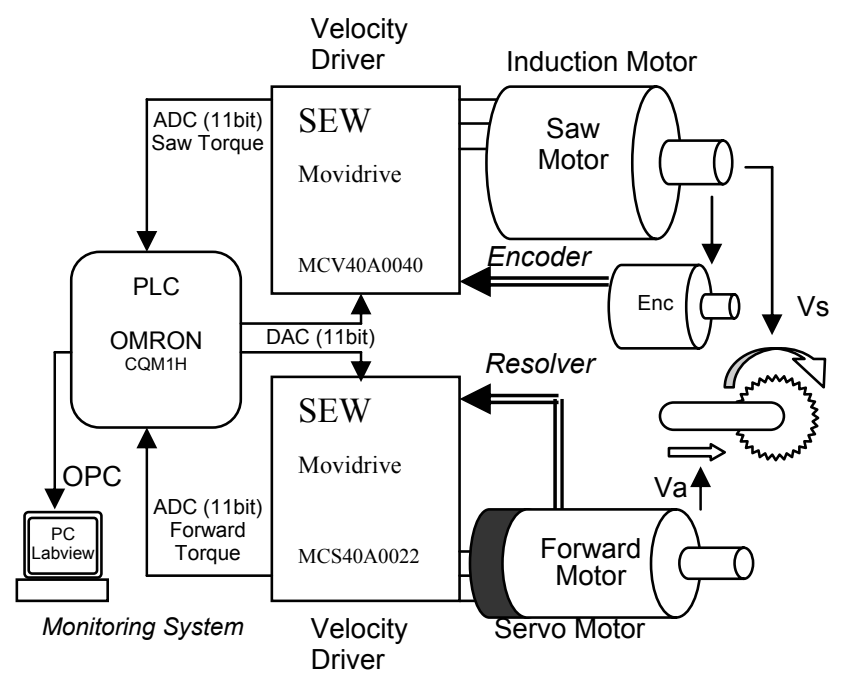

Fig. 7: Cutting-off system diagram.

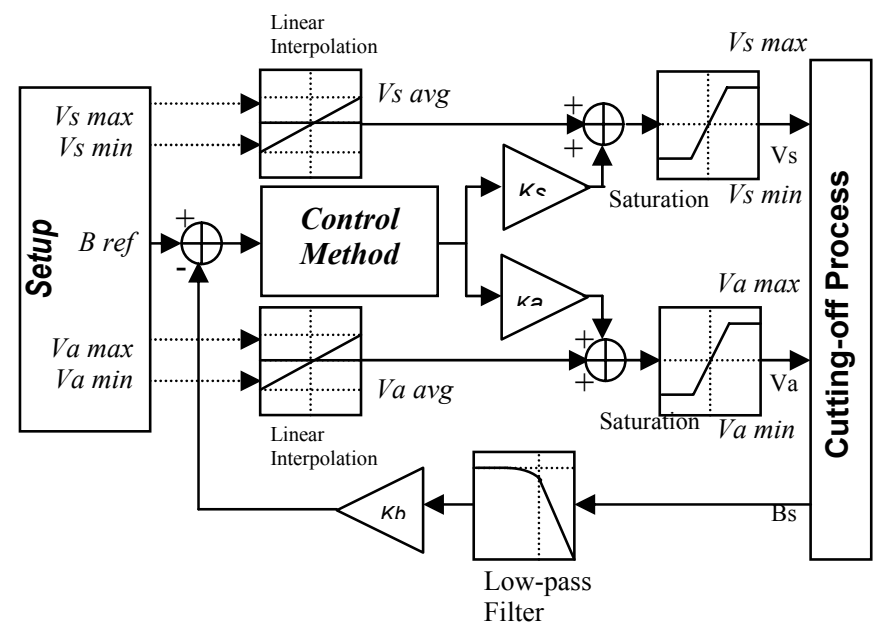

Fig. 8: Automatic velocity control Cutting-off Controller.

\subsection{Cutting-off Controller}

In Figure 8, a template of the controller implemented in this project is shown where the "Control Method" box can include a control method like PID, fuzzy controller, or other control strategies $[2,3]$. This control strategy uses a 


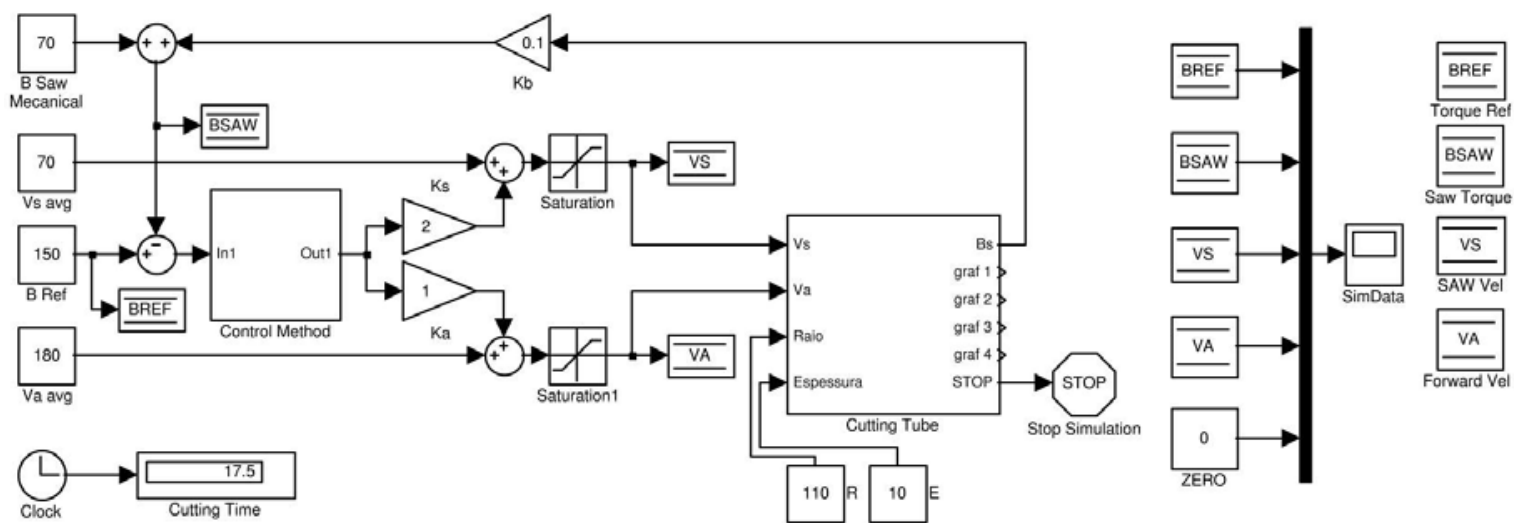

Fig 9: MatLab / Simulink model of the cutting-off controller

single reference, accordingly a single output is generated which in turn is used for calculation of angular and forward velocity of the saw. Also, the controller must guaranty at all times that the output values are always within the recommended range of values.

The reference torque ( $\mathrm{B}$ ref) allows the adjustment of the type of cutting to be performed, i.e., a low reference torque defines a soft/slow cut, whereas a high reference torque defines a hard/fast cutting.

The average angular velocity (Vs avg) and the average forward velocity (Va avg) are calculated using a linear interpolation. These average velocities are used as initial output values [4].

The controller input is the error between reference torque and saw disc filtered torque, and the output is generated according to the control method used.

\section{Cutting-off Models}

Models of the cutting process of a round tube and the cutting controller were developed using Matlab / Simulink. These models were used to validate the control methods and to gain more knowledge of the cutting-off process.

The model has saw velocity (Vs) and forward (Va) velocity as inputs, and it outputs the instantaneous cutting saw torque (Bs). The model also needs to know the pipe radius and thickness. If the thickness is equal to the radius we can simulate the cutting-off of a rod. The model also provides an output that can be used to terminate the simulation ("STOP" output).

The saw velocity must always be positive in order to get correct output values. The forward velocity input can either be positive or negative. In case of negative values the saw torque output is zero.

Figure 9 presents the Simulink block diagram used to simulate the cutting-off controller. In this diagram, the algorithms to detect the start and the end of cutting are not implemented. The controller to be tested must be inserted in the block "control method".

The saturation values and the average velocities were previously calculated.

\subsection{Simulation}

Using the above presented models, several simulations were carried out using always the same simulation parameters. A simulation of a cutting-off operation of a pipe with $110 \mathrm{~mm}$ of radius and $10 \mathrm{~mm}$ wall was performed and its results are presented in this paper. The main objective of theses simulations is the analysis of the cutting time and applied saw torque. The maximum value of the saw torque is very important because it allows the identification of the best controller. The simulation was intended for a machine with an ideal cutting saw torque of $120 \mathrm{Nm} \pm 20 \%$.

\subsection{Cutting using constant velocity}

Conventional cutting-off control is performed in open loop mode. These cuts are made at predefined constant velocities. Therefore, the applied saw torque variations depend on the shape, position and material to be removed [9].

In this simulation, saw torque maximum values are above $185.2 \mathrm{Nm}$, however most of the time saw torque values are quite low, around $100 \mathrm{Nm}$. The cutting time is proximately 17.5 seconds.

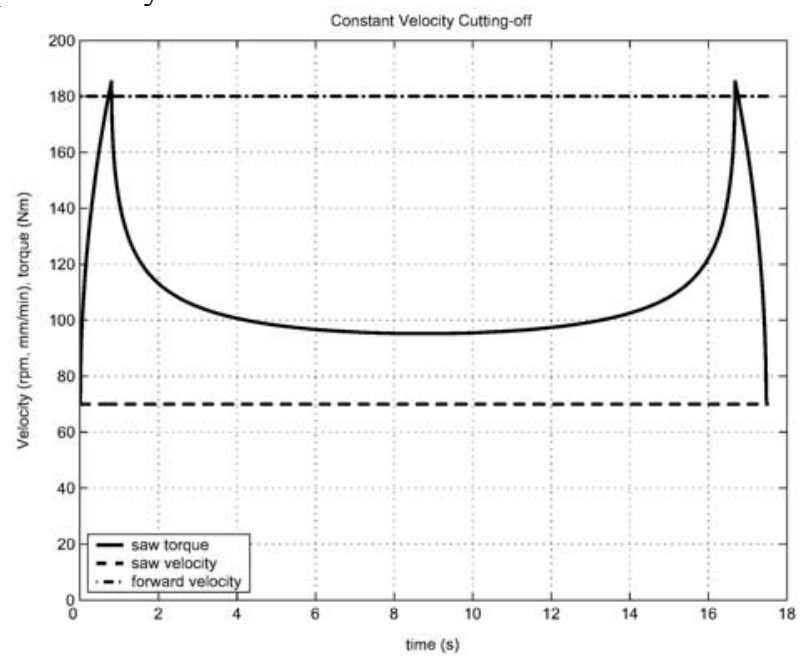




\subsection{Proportional controller cutting-off}

Using a proportional controller (see Figure 9), the variations of the saw and forward velocities can be seen. With a reference torque of $120 \mathrm{Nm}$, a maximum saw torque of $140 \mathrm{Nm}$ is recorded, were the saw velocity is saturated. In this case, the cutting time was of approximately of 14.2 seconds. Thus, a faster cut with a smaller maximum saw torque is obtained.

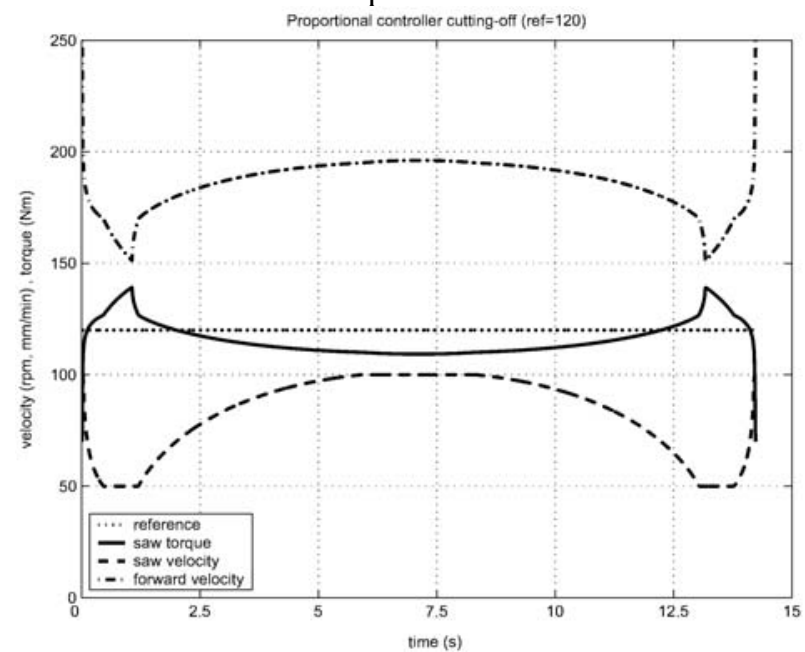

Fig. 9: Proportional controller cutting-off (ref $=120$ N.m).

\subsection{PI controller cutting-off}

In the Figure 10, the results of a the usage of a PI controller with a torque reference of $120 \mathrm{Nm}$ are shown. The cutting time is about 13.3" seconds. The controller can follow the reference even when the saw velocity saturates by increasing the forward velocity even more. This adjustment is the result of the PI integral part of the controller.

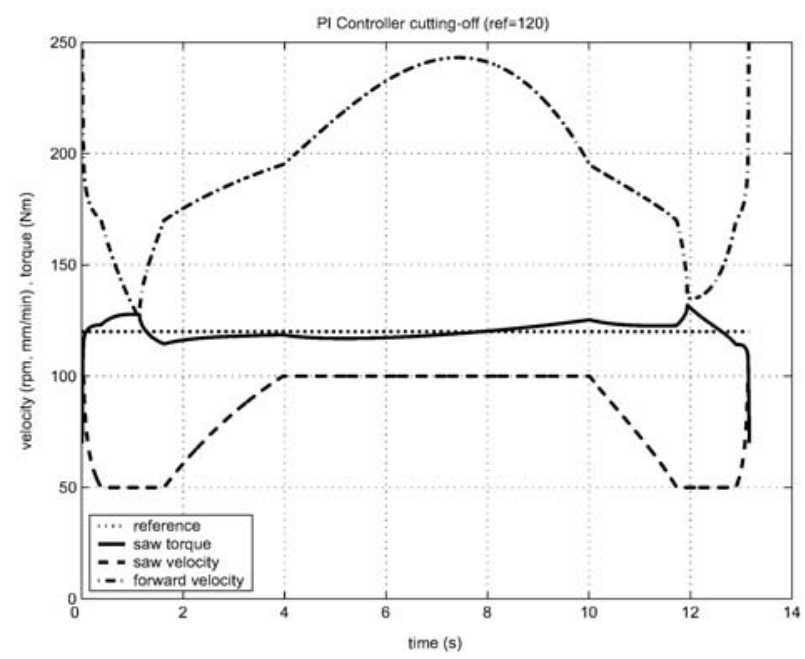

\subsection{Fuzzy controller cutting-off}

With a fuzzy controller an implementation of a soft-start is needed. The results are very good because cutting time is reduced to 13.2 seconds (see Figure 10).

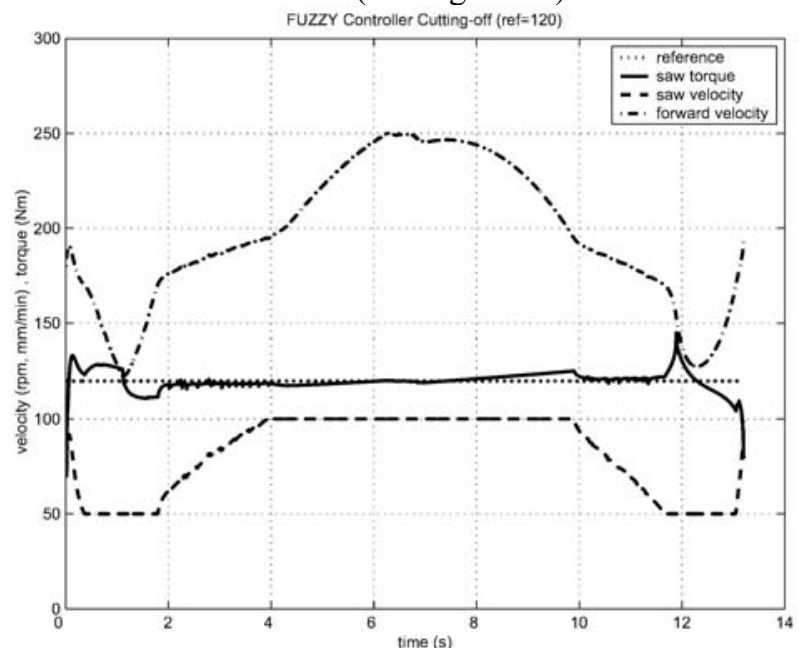

Fig. 10: Fuzzy controller Cutting-off (ref=120 N.m).

\subsection{Simulation results}

In Table 2 the most relevant results of different simulations are compared. Depending on the type of controller, one always gets better results in close loop rather than in open loop. Actually, a reduction of about $30 \%$ cutting time can be achieved. It is also possible to control the hardness and softness of the cutting mode.

On one hand, the higher the reference torque the smaller the cutting time will be. On other hand, the machine and saw will suffer greater wear.

The accumulated error can determine the best controller to be adopted. However, limitations on the actuators can limit the controller performance. Therefore, a control method must always be chosen based on the maximum value of the saw torque.

\begin{tabular}{|l|c|c|}
\hline \multicolumn{1}{|c|}{ Controller } & $\begin{array}{c}\text { Max Saw Torque } \\
\text { (N.m) }\end{array}$ & $\begin{array}{c}\text { Cutting Time } \\
\text { (s) }\end{array}$ \\
\hline $\begin{array}{l}\text { Constant Velocity } \\
\text { (Without controller) }\end{array}$ & 185 & $17.5 "$ \\
\hline $\begin{array}{l}\text { Proporcional } \\
\text { Controller }\end{array}$ & 139 & $14.2 ”$ \\
\hline PI Controller & 132 & $13.3 "$ \\
\hline Fuzzy Controller & 145 & $13.2 ”$ \\
\hline \multicolumn{2}{|c|}{ Table 2- Controller results } \\
\hline
\end{tabular}

\section{Experimental Results}

Experimental results were acquired with the machine working in automatic cutting cycle in an industrial environment.

Process monitoring is carried out using an OPC Server that permits the connection of a PLC to a personal computer PC that can run the Labview program (Figure 12). In monitoring system we can see the instantaneous and also the historical values of the saw torque, and the saw and forward velocities. The values 
exported by the PLC are obtained from the final output and input registers in order to debug the PLC calculations and to reduce transmitted data. This monitoring program can also run in a remote computer over any TCP/IP network.

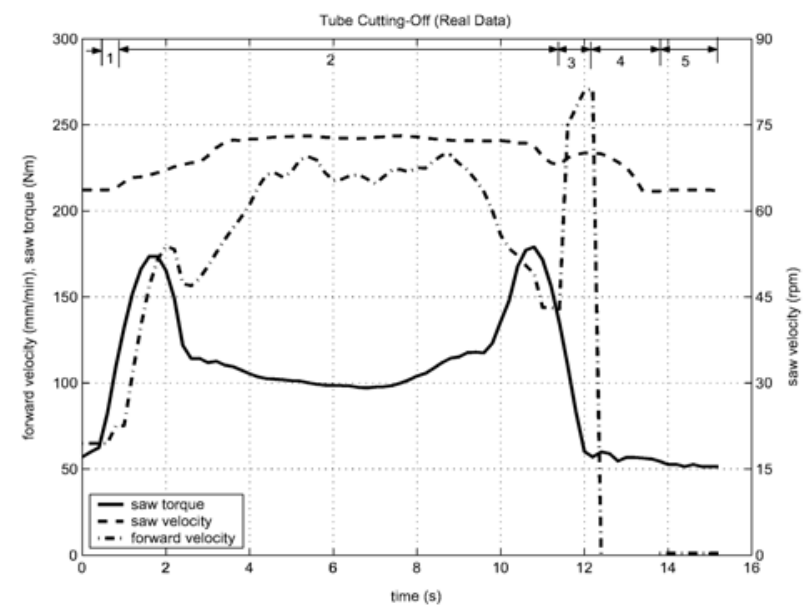

Fig. 11: Cutting-off of circular profile tube (real cutting-off data).

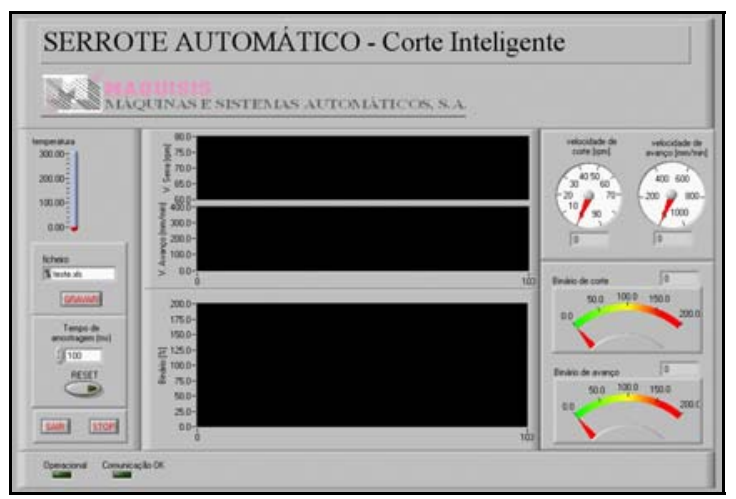

Fig. 12: LabView - Monitoring program Layout.

\begin{tabular}{|l|c|c|}
\hline \multicolumn{1}{|c|}{ Tube Cutting-off } & $\begin{array}{l}\text { Cutting } \\
\text { time (s) }\end{array}$ & $\begin{array}{c}\text { Saw cuts } \\
\text { per disc }\end{array}$ \\
\hline $\begin{array}{l}\text { circular profile (R=100mm E=10mm) } \\
\text { [standard cutting-off] }\end{array}$ & 25 & 800 \\
\hline $\begin{array}{l}\text { circular profile ( } \mathrm{R}=100 \mathrm{~mm} \text { E=10mm) } \\
\text { [Automatic Vel. } \text { Control cutting-off] } \\
\text { (nominal saw torque reference) }\end{array}$ & $14 . .18$ & 1000 \\
\hline $\begin{array}{l}\text { circular profile ( } \mathrm{R}=100 \mathrm{~mm} \text { E=10mm) } \\
\text { [Automatic Vel. Control } \text { cutting-off] } \\
\text { (low saw torque reference) }\end{array}$ & $24 . .26$ & 1500 \\
\hline $\begin{array}{l}\text { square profile (L=60mm E=20mm) } \\
\text { [standard cutting-off] }\end{array}$ & 40 & 300 \\
\hline $\begin{array}{l}\text { square profile (L=60mm E=20mm) } \\
\text { [Automatic Vel. Control cutting-off] } \\
\text { (nominal saw torque reference) }\end{array}$ & $40 . .45$ & 900 \\
\hline $\begin{array}{l}\text { square profile (L=60mm E=20mm) } \\
\text { [Automatic Vel. Control cutting-off] } \\
\text { (low saw torque reference) }\end{array}$ & $46 . .52$ & 1450 \\
\hline \multicolumn{2}{|l|}{ Table 3- Saw cuts per saw disc } \\
\hline
\end{tabular}

The parameters downloaded were: the saw velocity, the forward velocity and the saw torque. In this data, it is possible to identify all the automation process stages as above described.

In Figure 11, the real monitored data can be seen. It represents a tube with round profile cutting-off using a circular saw, with a proportional controller. The three curves shown in the figure represent the saw disc torque, saw rotation velocity and forward velocity. This process can be divided in four regions: Cutting-Start, Cutting, Cutting End, Moving back-wards the Saw. In the first region the cutting start is detected when the saw torque is higher than the threshold. In the second region, the cutting process occurs using a Proportional controller. In the third interval, it can be seen the detection of the completion of the cutting. The forward and saw velocities increase because there is no relevant saw torque for more than 1 second, subsequently, the saw starts moving backward.

\section{Conclusions and Future Work}

This control system was implemented in a commercially available industrial cutting-off machine. The controller runs on a PLC, because cost, reliability and safety are a major issue.

With a simple Proportional-Integral (PI) controller, much better cutting quality is achieved, with lower cycle time, lower wear of the saw disc and machine. As an example, a typical cut of a hollow metal tube using a traditional cutting-off machine takes about thirty seconds. With a simple PI controller cycle times are reduced to twenty seconds, with less wear of saw disc and machine.

Further, less disc changes are required as they last longer. Also, cutting-off machine set-up time (parameters configuration) is minimized due to, among other factors, the automatic detection of when the material has been completely cut.

Process monitoring is carried out using an OPC Server.

Currently, other alternatives to the PI controller are being implemented and tested in order to optimize the system.

\section{References}

[1] W. Velthuis, N. Brouwers, Mechatronics in Assembly Machines, Proc. Of Mechatronics 24-26 June 2002, University of Twente, 2002.

[2] W. Velthuis, N. Brouwers, Mechatronics in Assembly Machines, Proc. Of Mechatronics 24-26 June 2002, University of Twente, 2002.

[3] K. Astrom, B. Wittenmark, Computer Controlled Systems-Theory and Design, Prentice-Hall, ISBN 0-13-172784-2, 1990.

[4] J.-S. R. Jang, C.-T. Sun E. Mizutani. Neuro-Fuzzy And Soft Computing - A computational approach to learning and machine intelligence. Prentice-Hall Inc, ISBN 0-13-261066-3, 1997

[5] G. Franklin, J. Powell, M. Workman, Digital Control of Dynamic Systems, Addison Wesley, ISBN 0-201-33153-5, 1997.

[6] A. Cavallo, R. Setola, F. Vasca, Using Matlab, Simulink and controlsystem toolbox: A practical approach, Prentice Hall, Europe, UK, 1996

[7] MATLAB: High-performance Numeric Computation and Visualization Software-Reference Guide, The Math Works Inc., April 1993.

[8] SIMULINK: The dynamic system simulation software-user's guide, MathWorks Inc., April 1993

[9] A.F. Potvin, Nonlinear control design toolbox. The Math Works Inc., 1993

[10] Milton C. Shaw, Metal Cutting Principles, Oxford University Press, ISBN 0-19-859002-4, 1984 